\title{
Article \\ Smoking Cessation Rate and Its Predictors among Heavy Smokers in a Smoking-Free Hospital in Taiwan
}

\author{
Chin-Jung Lin ${ }^{1}$, Wei-Hsin Huang ${ }^{1,2,3} \mathbb{}$, Che-Yuan Hsu ${ }^{1}$, Jin-Jin Tjung ${ }^{1}$ and Hsin-Lung Chan ${ }^{1,2,3, *}$ \\ 1 Department of Family Medicine, Mackay Memorial Hospital, Taipei 106, Taiwan; \\ junglin20022002@yahoo.com.tw (C.-J.L.); whh5881@gmail.com (W.-H.H.); \\ passionhsu1120@gmail.com (C.-Y.H.); jinjin0921@gmail.com (J.-J.T.) \\ 2 Community Health Center, Mackay Memorial Hospital, Taipei 106, Taiwan \\ 3 Division of Medicine, Mackay Medical College, New Taipei City 252, Taiwan \\ * Correspondence: hunter5770@gmail.com; Tel.: +886-2-2543-3535; Fax: +886-2-25213847
}

\section{check for} updates

Citation: Lin, C.-J.; Huang, W.-H.; Hsu, C.-Y.; Tjung, J.-J.; Chan, H.-L. Smoking Cessation Rate and Its Predictors among Heavy Smokers in a Smoking-Free Hospital in Taiwan. Int. J. Environ. Res. Public Health 2021, 18, 12938. https://doi.org/10.3390/ ijerph182412938

Academic Editors: Paul

B. Tchounwou and Raymond S. Niaura

Received: 22 September 2021 Accepted: 6 December 2021 Published: 8 December 2021

Publisher's Note: MDPI stays neutral with regard to jurisdictional claims in published maps and institutional affiliations.

Copyright: (c) 2021 by the authors. Licensee MDPI, Basel, Switzerland. This article is an open access article distributed under the terms and conditions of the Creative Commons Attribution (CC BY) license (https:// creativecommons.org/licenses/by/ $4.0 /)$.

\begin{abstract}
Smoking poses critical risks for heart disease and cancers. Heavy smokers, defined as smoking more than 30 pack-year, are the most important target for smoking cessation. This study aimed to obtain the cessation rate and its predictors among heavy smokers. We collected data from heavy smokers who visited a smoking-free hospital in Taiwan during 2017. All patients were prescribed either varenicline or nicotine replacement therapy (NRT) for smoking cessation, and their smoking status was followed for six months. Successful smoking cessation was defined by selfreported no smoking over the preceding seven days (7-day point abstinence). In total, 280 participants with a mean aged of 53.5 years were enrolled, and $42.9 \%$ of participants successfully stopped smoking in 6 months. The results revealed that quitters were older, with hypertension, fewer daily cigarettes, and being prescribed with varenicline. Multiple logistic regressions analyses identified that fewer daily cigarettes and being prescribed with varenicline were predictors of successful smoking cessation. Therefore, we suggest that varenicline use may help heavy smokers in smoking cessation.
\end{abstract}

Keywords: heavy smoker; nicotine replacement therapy; quit smoking clinic; smoking cessation; varenicline; predictor

\section{Introduction}

Tobacco use is one of the leading public health problems that causes more than 8 million deaths per year in the world. Based on the World Health Organization statistics, 7 million deaths per year are related to direct tobacco use, and about 1 million deaths are related to exposure to secondhand smoke [1]. According to the National Health Interview Survey 2017 data, about 47.4 million adults are current smokers in the United States [2]. The prevalence of smoking in Taiwan is approximately 3.5 million, and more than 20,000 people died every year in ways related to tobacco use [3]. The rate of death from any cause among current smokers was about three times that among those who had never smoked, and smokers lose at least one decade of life expectancy compared with those who have never smoked [4].

Smoking intensity consists of smoking amount and smoking duration. It was calculated by multiplying the number of packs of cigarettes smoked per day by the number of years the subject has smoked. Thirty pack-year means smoking one pack per day for 30 years or two packs per day for 15 years. In the prospective cohort study, the daily cigarette count was associated with sudden cardiac death even without coronary heart disease at baseline [5]. In addition, smoking intensity posed a positive dose-response relationship with significant increases in lymphoma risk [6]. Based on the dose-response meta-analysis, the risk of stroke increased by $12 \%$ for each increment of five cigarettes per day [7]. In non-small cell lung cancer, the increase in pack-years was associated 
with decreased median overall survival [8]. In 2013, the American Cancer Society recommended lung cancer screening with low-dose computer tomography in persons aged 55 to 74 years who have $\geq$ a 30 pack-year smoking history, which was defined as a high-risk population [9].

Heavy smokers seem to be the most important target for smoking cessation, but few studies evaluate the predictors of smoking cessation in this group. In this study, we defined heavy smokers as smoking intensity $\geq 30$ pack-year. The purpose of the study was to find out the smoking cessation rate and its predictors of successful smoking cessation among heavy smokers in our smoking-free hospital.

\section{Materials and Methods}

\subsection{Study Populations/Subjects}

We performed a retrospective study from records of patients visiting the outpatient smoking cessation clinics in Mackay Memory Hospital in Taiwan from 1 January to 31 December 2017. All participants were over the age of 18 years old and were legally covered in the National Health Insurance Program in Taiwan, had a Fagerström Test of Nicotine Dependence (FTND) score equal to or greater than 4 or smoked more than 10 cigarettes per day. A total of 280 heavy smokers (smoking history $\geq 30$ pack-years) were included in the study. All participants were prescribed either varenicline or nicotine replacement therapy (NRT) for smoking cessation. Counseling for smoking cessation were provided by physicians and case managers. Telephone interviews of individual participants were conducted by case managers at the end of 2 weeks, 3 months, and 6 months after the participants' first clinic visit to assess their smoking condition and drug adherence.

\subsection{Data Collection and Outcome Measures}

The basic demographic data, including age, gender, body weight, medical history, and smoking history were obtained at the first outpatient clinic visit. Participants were asked about their smoking habits, including daily consumption of cigarettes and how many years have they been smoking. The FTND was used to assess their smoking dependence (scores range from 0 to 10, with higher scores representing greater nicotine dependence). In general, smokers with FTND $\geq 7$ may have strong withdrawal symptoms and relapse early [10]. Exhaled CO levels were assessed with a carbon monoxide monitor.

The participants were followed with telephone calls by case managers to collect information about their smoking status six months after the treatment. Those who selfreported as having stopped smoking were assumed to have successfully stopped smoking. Successful smoking cessation was defined by self-reported no smoking over the preceding seven days (7-day point abstinence) at six months follow-up.

\subsection{Statistical Analysis}

Data are expressed as means \pm SDs for continuous variables, and as percentages for categorical variables. We performed Student's $t$-test and a Chi-square test to detect significant differences among the variables between quitters and non-quitters. Multivariate logistic regression analysis was applied for assessments of the odds ratio (OR) of associated factors for smoking cessation. All statistical analyses were conducted using SPSS version 22.0(IBM Corp., Armonk, NY, USA). The criterion for statistical significance was $p<0.05$.

\subsection{Ethical Approval}

The study was performed with the approval of the Institutional Review Board of Mackay Memorial Hospital, Taipei, Taiwan (application number, 17MMHIS049).

\section{Results}

The characteristics of demographic data are shown in Table 1. The participants were mainly male $(82.5 \%)$, with a mean age of 53.5 years old. Because the participants were heavy smokers, the mean smoking years was 33 , the average daily cigarettes count was 
30.4, and the FTND score was 7.4. The average pharmacotherapy treatment duration was $5.9 \pm 4.3$ weeks. In all, $219(78.2 \%)$ participants received varenicline, and $61(21.8 \%)$ participants received NRT. The highest proportion of comorbidity was hyperlipidemia $(36.4 \%)$ and followed by hypertension (33.9\%).

Table 1. Participants' baseline characteristics.

\begin{tabular}{cc}
\hline & Total \\
Variable & $n=\mathbf{2 8 0}$ \\
& Mean \pm SD or N(\%) \\
\cline { 2 - 2 } & \\
\hline Age (years) & $53.5 \pm 10.1$ \\
Men & $231(82.5 \%)$ \\
Weight (kg) & $71.6 \pm 14.9$ \\
Smoking years (years) & $33.0 \pm 9.9$ \\
Cigarettes / day & $30.4 \pm 11.8$ \\
Exhaled CO (ppm) & $19.6 \pm 11.9$ \\
FTND score & $7.4 \pm 2.3$ \\
Pharmacotherapy duration (weeks) & $5.9 \pm 4.3$ \\
Pharmacotherapy with Varenicline & $219(78.2 \%)$ \\
Pharmacotherapy with NRT & $61(21.8 \%)$ \\
Hypertension & \\
Diabetes & $95(33.9 \%)$ \\
Hyperlipidemia & $63(22.5 \%)$ \\
Heart disease & $102(36.4 \%)$ \\
Lung disease & $39(13.9 \%)$ \\
Neurological disease & $15(5.4 \%)$ \\
Cancer & $19(6.8 \%)$ \\
Comorbidities & $15(6.4 \%)$ \\
\hline Depreviations: CO (ppm) = carbon monoxide (parts per million); FTND score $=$ Fagerström Test of Nicotine
\end{tabular}

The comparison of baseline characteristics among quitters and non-quitters is shown in Table 2. Overall, there were $120(42.9 \%)$ participants who had successfully quit smoking within six months. Compared with non-quitters, quitters were older, smoking less than 30 cigarettes per day, prescribed with varenicline, and with comorbidity of hypertension. There was no significant difference between the quitters and non-quitters in terms of gender, body weight, smoking duration, exhaled CO concentration, FTND, duration of pharmacotherapy treatment, comorbidity of diabetes, hyperlipidemia, heart disease, lung disease, neurological disease, and cancer.

With multiple logistic regression analysis for odds ratio (OR) of associated factors for smoking cessation, the results showed heavy smokers who used varenicline and successfully quit smoking in 6 months outnumbered those who used NRT (OR: 2.44, 95\% Confidence interval (CI): 1.26-4.74) and the daily cigarette count was negatively associated with smoking cessation (OR: 0.97, 95\% CI: 0.95-0.99) (Table 3). 
Table 2. Comparison of baseline characteristics related to smoking cessation among quitters and non-quitters.

\begin{tabular}{cccc}
\hline & $\begin{array}{c}\text { Quitters } \\
(\mathbf{n = 1 2 0 )} \\
\mathbf{( 4 2 . 9 \% )}\end{array}$ & $\begin{array}{c}\text { Non-Quitters } \\
(\boldsymbol{n}=\mathbf{1 6 0 )} \\
\mathbf{( 5 7 . 1 \% )}\end{array}$ & $p$ Value * \\
\hline Variable & & Mean \pm SD or N(\%) & \\
\hline Demographics & & & 0.0058 \\
\hline Age (years) & $55.4 \pm 9.9$ & $50.5 \pm 10.1$ & 0.7506 \\
Men & $100(83.3 \%)$ & $131(81.9 \%)$ & 0.8104 \\
Weight (kg) & $71.9 \pm 14.7$ & $71.4 \pm 15.1$ & 0.1392 \\
Smoking years (years) & $34.0 \pm 10.0$ & $32.3 \pm 9.8$ & 0.0025 \\
Cigarettes/day & $27.9 \pm 10.5$ & $32.2 \pm 12.5$ & 0.0525 \\
Exhaled CO (ppm) & $18.1 \pm 12.3$ & $20.8 \pm 11.5$ & 0.1872 \\
FTND score & $7.2 \pm 2.3$ & $7.5 \pm 2.3$ & 0.132 \\
Pharmacotherapy & $6.3 \pm 4.4$ & $5.5 \pm 4.3$ & 0.003 \\
duration (weeks) & & & \\
Pharmacotherapy & $104(86.7 \%)$ & $115(71.9 \%)$ & 0.114 \\
with Varenicline & & & \\
Pharmacotherapy & $16(13.3 \%)$ & $45(28.1 \%)$ & 0.0346 \\
with NRT & & & 0.3856 \\
Comorbidities & $49(40.8 \%)$ & $46(28.8 \%)$ & 0.2822 \\
Hypertension & $24(20.0 \%)$ & $39(24.4 \%)$ & 0.6538 \\
Diabetes mellitus & $48(40.0 \%)$ & $54(33.8 \%)$ & 0.3994 \\
Hyperlipidemia & $18(15.0 \%)$ & $21(13.1 \%)$ & 0.7593 \\
Heart disease & $8(6.7 \%)$ & $7(4.4 \%)$ & $(6.3 \%)$ \\
Lung disease & $9(7.5 \%)$ & $8(5.0 \%)$ & \\
Neurologic disease & $7(5.8 \%)$ & & \\
Cancer & & & \\
\hline
\end{tabular}

Abbreviations: $\mathrm{CO}(\mathrm{ppm})=$ carbon monoxide (parts per million); FTND score = Fagerström Test of Nicotine Dependence score; NRT = nicotine replacement therapy; * Using Chi-square and $t$-test.

Table 3. Odds ratio (95\% confidence interval) among quitters and non-quitters' groups with logistic regression analysis.

\begin{tabular}{ccc}
\hline & \multicolumn{2}{c}{ Quitters vs. Non-Quitters } \\
\cline { 2 - 3 } & Odds Ratio (95\% CI) & $p$ Value \\
\hline Age (years) & $1.02(0.99-1.05)$ & 0.171 \\
Hypertension & $1.42(0.82-2.46)$ & 0.205 \\
Daily cigarette count & $0.97(0.95-0.99)$ & 0.041 \\
Pharmacotherapy (Varenicline & $2.44(1.26-4.74)$ & 0.008 \\
vs. NRT) & \\
\hline Abbreviations: FTND score = Fagerström Test of Nicotine Dependence score; NRT = nicotine replacement therapy.
\end{tabular}

\section{Discussion}

Studies have emphasized a strong dose-dependent relationship between smoking amount and related diseases' outcomes [7,11]. Heavy smokers have higher risks for associated diseases, so the physicians should advise them more actively to quit smoking. According to a previous study, heavy smokers have some characteristics, such as being male, have used quitting aids before, have other substances used, more alcohol abuse, depression, and lower confidence in quitting [12]. Without being advised by health professionals, the heavy smokers have a relative lower smoking cessation rate. Smokers who undergo smoking cessation programs, a combination of drug therapies and behavioral change instruction are five times more successful in quitting smoking than smokers who attempt to quit on their own [13]. In 2017, an average 6-month success rate of stopping smoking is $28.8 \%$ according to the Health Promotion Administration in Taiwan [14]. In our study, $42.9 \%$ of heavy smokers had successfully stopped smoking within 6 months. The higher 
success rate may be related to the explanation concerning the benefits of stopping smoking, the doctor's encouragement, the case manager's regular follow-up telephone call, the lesser adverse reaction of varenicline, and the payment of only USD 10 per visit. Although the smoking cessation rate of heavy smokers was low, active promotion of smoking cessation programs can still help increase the cessation rate [15].

One study showed that smoking cessation was more common with increasing age, higher education and fewer years of smoking. Asthma, wheeze, hay fever, chronic bronchitis, diabetes, and hypertension did not significantly predict smoking cessation, but smokers hospitalized for ischemic heart disease during the study period were more prone to stopping smoking [16]. In our study, older age and comorbidity of hypertension were significantly different between quitters and non-quitters, but the logistic regression analysis did not show that they were the predictors of smoking cessation. Nicotine in cigarettes may increase the blood pressure. Quitting smoking and lowering blood pressure are more likely to be noticed by smokers than lowering blood sugar or lipids. This might be the reason why comorbidity of hypertension was significantly different between quitters and non-quitters.

One study in Taiwan stratified FTND (low: 0-3; medium: 4-6; high: $\geq 7$ ) and indicated a lower FTND is a predictor of success smoking cessation [17]. However, our study showed the average FTND score among the heavy smokers was 7.4 and there was no significant difference between quitters and non-quitters based on FTND. The reason might be that the participants were all heavy smokers with high FTND level. The reason for higher smoking cessation rate in men is that women have more concerns about the negative outcome of smoking cessation, including weight gain [18]; however, in our study, gender had no significant difference in smoking cessation among heavy smokers

An analysis of cohort study, lower levels of daily cigarettes count was the predictor of smoking cessation [19]. In our study, the mean daily cigarettes count among heavy smokes was 30.4 (SD 11.8). There was significant difference between quitters and nonquitters in terms of daily cigarettes fewer than or more than 30 per day. Logistic regression analysis also showed fewer daily cigarettes was the predictor of smoking cessation (OR: 0.97 [0.95-0.99]).

In clinical settings, smoking cessation medication was prescribed individually according to each participant's medical condition. In our study, 120 (42.9\%) participants successfully quit smoking in 6 months and the proportion of quitters using varenicline was significantly higher than that of non-quitters. The study revealed that varenicline use might help in smoking cessation in heavy smokers compared to NRT. Previous studies also show that comparison of varenicline with NRT or bupropion, varenicline has significantly greater efficacy for smoking cessation [20-22]. Varenicline reduces the symptoms of nicotine withdrawal by binding with high affinity and acting as a partial agonist at the alpha- 4 beta- 2 nicotine receptor. Through its stimulating effects of the receptor, it reduces the cravings of smokers. Varenicline also blocks nicotine from binding to the receptor, interrupting the reinforcing effects of nicotine that lead to nicotine dependence. Through this action, it reduces the rewarding aspects of cigarettes smoking. In our study, the average FTND score of participants was 7.4, which means a high dependence and craving for nicotine. Varenicline's mechanism of action might be the reason why varenicline is better than NRT for heavy smokers.

\section{Conclusions}

Heavy smokers pose a higher risk of associated diseases, so the physicians should put more effort into these populations on smoking cessation. Heavy smokers with fewer daily cigarettes were more likely to quit smoking. We also suggest that varenicline use may help in smoking cessation among heavy smokers.

Author Contributions: H.-L.C.: conceptualization and supervision. C.-J.L.: visualization and writing-original draft. W.-H.H.: methodology and project administration. C.-Y.H.: data curation and formal analysis. J.-J.T.: writing-review and editing. All authors have read and agreed to the published version of the manuscript. 
Funding: This research received no external funding.

Institutional Review Board Statement: The study was performed with the approval of the Institutional Review Board of Mackay Memorial Hospital, Taipei, Taiwan (application number, 17MMHIS049).

Informed Consent Statement: Not applicable.

Data Availability Statement: A retrospective study from records of patients visiting the outpatient smoking cessation clinics in Mackay Memory Hospital in Taiwan from 1 January to 31 December 2017.

Conflicts of Interest: The authors declare no conflict of interest.

$\begin{array}{ll}\text { Abbreviations } \\ \text { CI } & \text { Confidence interval; } \\ \text { CO } & \text { Carbon monoxide; } \\ \text { FTND } & \text { Fagerström test for nicotine dependence; } \\ \text { NRT } & \text { Nicotine replacement therapy; } \\ \text { OR } & \text { Odds ratiol } \\ \text { ppm } & \text { Parts per million. }\end{array}$

\section{References}

1. World Health Organization. WHO Report on the Global Tobacco Epidemic, 2017: Monitoring Tobacco Use and Prevention Policies; World Health Organization: Geneva, Switzerland, 2017; Available online: https://apps.who.int/iris/handle/10665/255874 (accessed on 1 September 2021).

2. National Center for Health Statistics. Survey Description, National Health Interview Survey; NCHS: Washington, DC, USA, 2017.

3. HPA. Adult Smoking Behavior Survey; Health Promotion Administration, Ministry of Health and Welfare: Taipei, Taiwan, 2018. Available online: https:/ / www.hpa.gov.tw / Pages /List.aspx?nodeid=1710 (accessed on 1 September 2021).

4. Jha, P.; Ramasundarahettige, C.; Landsman, V.; Rostron, B.; Thun, M.; Anderson, R.N.; McAfee, T.; Peto, R. 21st-century hazards of smoking and benefits of cessation in the United States. N. Engl. J. Med. 2013, 368, 341-350. [CrossRef] [PubMed]

5. Sandhu, R.K.; Jimenez, M.C.; Chiuve, S.E.; Fitzgerald, K.C.; Kenfield, S.A.; Tedrow, U.B.; Albert, C.M. Smoking, smoking cessation, and risk of sudden cardiac death in women. Circ. Arrhythmia Electrophysiol. 2012, 5, 1091-1097. [CrossRef] [PubMed]

6. Taborelli, M.; Montella, M.; Libra, M.; Tedeschi, R.; Crispo, A.; Grimaldi, M.; Maso, L.D.; Serraino, D.; Polesel, J. The dose-response relationship between tobacco smoking and the risk of lymphomas: A case-control study. BMC Cancer 2017, 17, 421. [CrossRef] [PubMed]

7. Pan, B.; Jin, X.; Jun, L.; Qiu, S.; Zheng, Q.; Pan, M. The relationship between smoking and stroke: A meta-analysis. Medicine 2019, 98, e14872. [CrossRef] [PubMed]

8. Janjigian, Y.Y.; McDonnell, K.; Kris, M.G.; Shen, R.; Sima, C.S.; Bach, P.B.; Rizvi, N.A.; Riely, G.J. Pack-years of cigarette smoking as a prognostic factor in patients with stage iiib/iv nonsmall cell lung cancer. Cancer 2010, 116, 670-675. [CrossRef] [PubMed]

9. Wender, R.; Fontham, E.T.; Barrera, E., Jr.; Colditz, G.A.; Church, T.R.; Ettinger, D.S.; Etzioni, R.; Flowers, C.R.; Gazelle, G.S.; Kelsey, D.K.; et al. American cancer society lung cancer screening guidelines. CA Cancer J. Clin. 2013, 63, 107-117. [CrossRef] [PubMed]

10. Caponnetto, P.; Polosa, R. Common predictors of smoking cessation in clinical practice. Respir. Med. 2008, 102, 1182-1192. [CrossRef] [PubMed]

11. Bhat, V.M.; Cole, J.W.; Sorkin, J.D.; Wozniak, M.A.; Malarcher, A.M.; Giles, W.H.; Stern, B.J.; Kittner, S.J. Dose-response relationship between cigarette smoking and risk of ischemic stroke in young women. Stroke 2008, 39, 2439-2443. [CrossRef] [PubMed]

12. Nguyen, M.A.; Reitzel, L.R.; Kendzor, D.E.; Businelle, M.S. Perceived cessation treatment effectiveness, medication preferences, and barriers to quitting among light and moderate/heavy homeless smokers. Drug Alcohol Depend. 2015, 153, 341-345. [CrossRef] [PubMed]

13. Laniado-Laborín, R. Smoking cessation intervention: An evidence-based approach. Postgrad. Med. 2010, 122, 74-82. [CrossRef] [PubMed]

14. HPA. Taiwan Tobacco Control Annual Report 2017; Health Promotion Administration, Ministry of Health and Welfare: Taipei, Taiwan, 2017.

15. Komiyama, M.; Takahashi, Y.; Tateno, H.; Mori, M.; Nagayoshi, N.; Yonehara, H.; Nakasa, N.; Haruki, Y.; Hasegawa, K. Support for patients who have difficulty quitting smoking: A review. Intern. Med. 2019, 58, 317-320. [CrossRef] [PubMed]

16. Holm, M.; Schiöler, L.; Andersson, E.; Forsberg, B.; Gislason, T.; Janson, C.; Jogi, R.; Schlünssen, V.; Svanes, C.; Torén, K. Predictors of smoking cessation: A longitudinal study in a large cohort of smokers. Respir. Med. 2017, 132, 164-169. [CrossRef] [PubMed]

17. Huang, W.H.; Hsu, H.Y.; Chang, B.C.; Chang, F.C. Factors Correlated with Success Rate of Outpatient Smoking Cessation Services in Taiwan. Int. J. Environ. Res. Public Health 2018, 15, 1218. [CrossRef] [PubMed]

18. Wetter, D.W.; Kenford, S.L.; Smith, S.S.; Fiore, M.C.; Jorenby, D.E.; Baker, T.B. Gender differences in smoking cessation. J. Consult. Clin. Psychol. 1999, 67, 555-562. [CrossRef] [PubMed] 
19. Hymowitz, N.; Cummings, K.M.; Hyland, A.; Lynn, W.R.; Pechacek, T.F.; Hartwell, T.D. Predictors of smoking cessation in a cohort of adult smokers followed for five years. Tob. Control 1997, 6 (Suppl. S2), S57-S62. [CrossRef] [PubMed]

20. Gonzales, D.; Rennard, S.I.; Nides, M.; Oncken, C.; Azoulay, S.; Billing, C.B.; Watsky, E.J.; Gong, J.; Williams, K.E.; Reeves, K.R. Varenicline, an alpha4beta2 nicotinic acetylcholine receptor partial agonist, vs sustained-release bupropion and placebo for smoking cessation: A randomized controlled trial. JAMA 2006, 296, 47-55. [CrossRef] [PubMed]

21. Aubin, H.J.; Bobak, A.; Britton, J.R.; Oncken, C.; Billing, C.B., Jr.; Gong, J.; Williams, K.E.; Reeves, K.R. Varenicline versus transdermal nicotine patch for smoking cessation: Results from a randomised open-label trial. Thorax 2008, 63, 717-724. [CrossRef] [PubMed]

22. Chang, C.P.; Huang, W.H.; You, C.H.; Hwang, L.C.; Lu, I.J.; Chan, H.L. Factors correlated with smoking cessation success in older adults: A retrospective cohort study in Taiwan. Int. J. Environ. Res. Public Health 2019, 16, 3462. [CrossRef] [PubMed] 